\title{
Characteristics, hospital referrals and 60-day mortality of older patients living in nursing homes with COVID-19 assessed by a liaison geriatric team during the first wave: a research article
}

Lorena García-Cabrera1*, Noelia Pérez-Abascal², Beatriz Montero-Errasquín², Lourdes Rexach Cano', Jesús Mateos-Nozal ${ }^{2}$ and Alfonso Cruz-Jentoft ${ }^{2}$

\begin{abstract}
Background: The infection by SARS-CoV-2 (COVID-19) has been especially serious in older patients. The aim of this study is to describe baseline and clinical characteristics, hospital referrals, 60-day mortality, factors associated with hospital referrals and mortality in older patients living in nursing homes $(\mathrm{NH})$ with suspected COVID-19.

Methods: A retrospective observational study was performed during March and April 2020 of institutionalized patients assessed by a liaison geriatric hospital-based team. Were collected all older patients living in 31 nursing homes of a public hospital catchment area assessed by a liaison geriatric team due to the suspicion of COVID-19 during the first wave, when the hospital system was collapsed. Sociodemographic variables, comprehensive geriatric assessment, clinical characteristics, treatment received including care setting, and 60-days mortality were recorded from electronic medical records. A logistic regression analysis was performed to analyze the factors associated with mortality.

Results: 419 patients were included in the study (median age 89 years old, $71.6 \%$ women, $63.7 \%$ with moderatesevere dependence, and $43.8 \%$ with advanced dementia). $31.1 \%$ were referred to the emergency department in the first assessment, with a higher rate of hospital referral in those with better functional and mental status. COVID-19 atypical symptoms like functional decline, delirium, or eating disorders were frequent.

$36.9 \%$ had died in the 60 days following the firstcall. According to multivariate logisticregression age ( $p 0.010)$, Barthel index $<60$ ( $p$ 0.002), presence of tachypnea( $p 0.021$ ), fever ( $p 0.006$ ) and the use of ceftriaxone ( $p 0.004)$ were associatedwith mortality. No mortality differences were found between those referred tothe hospital or cared at the nursing home.
\end{abstract}

Conclusions and implications: $31 \%$ of the nursing home patients assessed by aliaison geriatric hospital-based team for COVID-19 were referred to thehospital, being more frequently referred those with a better functional and

\footnotetext{
*Correspondence: Igcabrera@salud.madrid.org

${ }^{1}$ Unidad de Cuidados Paliativos, Hospital Universitario Ramón y Cajal

(IRYCIS), Carretera de Colmenar km 9,1, 28034 Madrid, Spain

Full list of author information is available at the end of the article
}

(C) The Author(s) 2021. Open Access This article is licensed under a Creative Commons Attribution 4.0 International License, which permits use, sharing, adaptation, distribution and reproduction in any medium or format, as long as you give appropriate credit to the original author(s) and the source, provide a link to the Creative Commons licence, and indicate if changes were made. The images or other third party material in this article are included in the article's Creative Commons licence, unless indicated otherwise in a credit line to the material. If material is not included in the article's Creative Commons licence and your intended use is not permitted by statutory regulation or exceeds the permitted use, you will need to obtain permission directly from the copyright holder. To view a copy of this licence, visit http://creativecommons.org/licenses/by/4.0/. The Creative Commons Public Domain Dedication waiver (http://creativeco mmons.org/publicdomain/zero/1.0/) applies to the data made available in this article, unless otherwise stated in a credit line to the data. 
cognitivesituation. The 60-days mortality rate due to COVID-19 was $36.8 \%$ and wasassociated with older age, functional dependence, the presence of tachypnea andfever, and the use of ceftriaxone. Geriatric comprehensive assessment andcoordination between $\mathrm{NH}$ and the hospital geriatric department teams werecrucial.

Keywords: COVID-19, Mortality, Nursing homes, Liaison geriatric team

\section{Background}

The coronavirus disease 2019 (COVID-19) was declared a pandemic on March 11, 2020, by the World Health Organization. The severity of this disease increases with age, with a mortality rate in those over 80 years of age between 20 and $30 \%,[1,2]$ and deaths in nursing homes $(\mathrm{NH})$ that represent up to $50 \%$ of total mortality, with a huge variability between countries [3, 4]. However, the analysis of 30-days mortality in hospitalized patients over 65 years old seems to be similar to that observed in nursing homes [5-7] and a relationship has been described between mortality of institutionalized patients due to COVID-19 with the male sex, cognitive and physical impairments, frailty, the presence of dyspnea or severe forms of the disease [8].

During the first wave of SARS CoV-2, a liaison geriatric hospital-based team was created in different hospitals of the Madrid region for the assessment of older patients in $\mathrm{NH}$, supporting on site care and treatment, or recommending referral to emergency departments for acute cases when needed [7,9]. At that time (first wave) the hospital system in Madrid was almost collapsed, with $105 \%$ of the beds occupied by COVID-19 patients [10].

In Spain, it has been calculated $47-50 \%$ of deaths by COVID-19 in the first wave occurred in this population, [4] which has generated a debate on the suitability of healthcare in the NH during the first wave. Recently, a study has been published where 30-day survival rate of institutionalized older patients with COVID-19 did not depend of where they were treated [7].

There are some published information on the clinical differences in institutionalized and COVID-19-infected older persons treated in their $\mathrm{NH}$ or referred to the hospital. However, in most of the available studies, either there is no follow-up or this follow-up is restricted to the first 30 days when it is known that the consequences and repercussions of this disease are prolonged in a longer period in many cases.

Therefore, our study aims to describe the clinical characteristics, the hospital referrals, the 60-day mortality, and the factors related including care setting (NH vs. hospital) in institutionalized patients with COVID-19.

\section{Methods}

A retrospective observational study of institutionalized patients with COVID-19 (clinical suspected or confirmed) who required telephone assessment from a liaison geriatric hospital-based team between 30 March and 30 April 2020 was performed. This team assessed any older patients from $31 \mathrm{NH}$ patients between 8 a.m. and 10 p.m. from Monday to Sunday. During this period the hospital had to increase the number of beds from some 750 to a peak of 983 , most of them filled by COVID-19 patients, and to increase fourfold the number of ICU beds [11].

We included all patients assessed for COVID-19 clinical suspicion (presence of respiratory symptoms, fever, delirium, functional impairment, decrease or eating disorders, with no alternative diagnosis) or with a confirmation of diagnostic test of active infection (SARSCoV-2 PCR availability was very limited in the first weeks of March and increased exponentially thereafter). We excluded older patients assessed for other reasons or patients assessed living in disable person centers.

We collected the following variables from clinical records based on the information provided by the $\mathrm{NH}$ healthcare professionals: age, sex, nursing home type, Barthel index, Functional Assessment Classification (FAC) for gait, Reisberg's Global Deterioration Scale for dementia staging (GDS), Charlson index, and malnutrition (BMI $<22$ in the last year, albumin $<3.5 \mathrm{~g} / \mathrm{dl}$ in the 6 months prior or active prescription of nutritional supplements). Also, we recorded COVID-19 related symptoms and date of onset (cough, dyspnea, falls, delirium, functional impairment related to asthenia, general malaise or deterioration of physical capacity, eating disorder defined as hyporexia, refusal to eat, or inability to use the oral route), as well as signs of COVID-19 severity (respiratory failure defined as oxygen saturation less than $92 \%$, dyspnea, tachypnea, referred to as more than 30 breaths per minute and a measured fever $\geq 38^{\circ} \mathrm{C}$ ), and COVID19 diagnostic test, prescribed treatments (hydroxychloroquine, lopinavir/ritonavir, antibiotic therapy, corticosteroid therapy, low molecular weight heparin), emergency department referrals, hospital admissions, and 60-day mortality. Hydroxychloroquine was used with the prior verbal consent of the patient or relatives, who were informed of its use outside the technical data specifications. 
In patients referred to the hospital after the first telephone assessment, we reviewed the result of the PCR for COVID-19, whether they required hospital admission and the length of hospitalization.

A descriptive analysis was performed with measures of frequency, mean, and deviation using the Chi-square test for qualitative variables and U-Mann -Whitney for quantitative variables with non-normal distribution. Also, a univariate and multivariate logistic regression model was used for 60-day mortality analysis. Significance was established at $p<0.05$. Data analysis was performed using the IBM SPSS Statistics version 20.

The study was approved by the Ethics Committee for Healthcare (Comité de Ética para la Asistencia Sanitaria, CEAS) of the Hospital (approved June 8, 2020, act 393). Informed consent was waived for this retrospective study. All the ethical principles for medical investigation in human beings recorded in the Helsinki declaration of the World Medical Association were followed.

\section{Results}

511 patients were assessed between March 30 and April 30 with an average number of 1.51 calls per patient and a range between 1 and 8 . We excluded 92 patients assessed for other reasons with a final sample of 419. Among our population 196 (46.8\%) had a positive COVID-19 diagnostic test.

\section{Participant's characteristics}

Patient characteristics are shown on Table 1, and correspond with a usual $\mathrm{NH}$ population of extreme old age and severe physical and mental disability. COVID-19 symptoms were mostly respiratory, but included geriatric syndromes as falls, delirium or refusal to eat. The median from symptom onset to telephone consultation was 3 days. The most used treatments were hydroxychloroquine $(64.2 \%)$, azithromycin $(53.2 \%)$, and ceftriaxone (29.4\%).

$31 \%$ were referred to the emergency department, $79 \%$ of them were hospitalized with an average length of stay of 9.1 days and an average time of emergency department referral since the onset of the symptoms of 9.3 days.

Hospital mortality was $27.7 \%$ and 60 -day mortality was $36.8 \% .70 .1 \%$ of deaths happened in the $\mathrm{NH}, 28 \%$ in the hospital, and $1.9 \%$ in a palliative care center.

\section{Patient characteristics according to the place of care (Table 1)}

Patients referred to the hospital had a better functional and mental status (Barthel $<6043.9 \%$ vs. $73 \%, p<0.001$, $\mathrm{FAC}<334.3 \%$ vs. $63.1 \%, p<0.001$, GDS $6-722.4 \%$ vs. $54 \%, p<0.001)$. Hospital referral was also associated with male gender ( $40 \%$ vs. $23.2 \%, p<0.001)$, and with the presence of severe symptoms like respiratory failure ( $81.5 \%$ vs. $65.1 \%, p<0.001)$, dyspnea ( $23.8 \%$ vs. $12.8 \%, p$ $<0.001$ ), functional decline ( $30 \%$ vs. $15.6 \%, p<0.001)$ or falls $(9.2 \%$ vs. $1.4 \%, p<0.001)$.

Patients referred at hospital after the first phone assessment received more frequently the following treatments: hydroxychloroquine $(75.4 \%$ vs. $59.2 \%, p 0.001)$, azithromycin $(64.6 \%$ vs. $48.1 \%, p$ 0.002), ceftriaxone $(47.7 \%$ vs. $21.1 \%, p<0.001)$, other antibiotics $(45.4 \%$ vs. $20.8 \%$, $p<0.001)$ corticosteroids $(46.2 \%$ vs. $18 \%, p<0.001)$ and low molecular weight heparin $(63.1 \%$ vs. $6.6 \%, p<0.001)$. Those patients who were referred on the first call and returned to the residence were more frequently referred back to the hospital than those who had not been referred initially (13.2\% vs. $4.5 \%, p$ 0.002) (Table 1$)$.

No differences in hospital referrals were found in terms of age, comorbidity, type of nursing home, time of evolution from the onset of symptoms, or mortality at 60 days.

\section{Factors related to 60 -day mortality (Table 2 )}

The mortality at 60 days was $36.8 \%$ and was associated in univariate analysis with functional and mental impairment (Barthel $<6075 \%$ vs. $57.3 \%, p<0.001$; FAC $<3$ $69.4 \%$ vs. $46.8 \%, p<0.001$ and GDS $6-750.7 \%$ vs. $39.9 \%$, $p 0.026)$ and presence of malnutrition $(72.2 \%$ vs. $59.8 \%$, $p$ 0.026). There was also a relationship with respiratory failure $(79.9 \%$ vs. $64.5 \%, p<0.001)$, tachypnea $(30.5 \%$ vs. $12.1 \%, p<0.001)$, fever ( $57.4 \%$ vs. $36.2 \%, p<0.001)$, delirium ( $25.3 \%$ vs. $16.2 \%)$ and eating disorders ( $24 \%$ vs. $15.5 \%, p 0.03)$.

No differences were found in mortality according to comorbidity, hospital referral (34.3\% vs. $29.1 \% p 0.253)$, sex, type of nursing home, time of evolution from the onset of symptoms or to the administration of the different treatments except the use of ceftriaxone, which was more frequent among the deceased $(40.9 \%$ vs. $22.6 \%, p$ $<0.001)$.

In 60-days mortality multivariate analysis, a significant association was observed with age [OR 1.05 (CI 1.011.09) $p$ 0.010], functional dependence measured as Barthel <60 [OR 2.57 (CI 1.4-4.7) $p$ 0.002], tachypnea [OR 2.12 (CI 1.12-4.01) $p$ 0.021], fever [OR 1.9 (CI 1.21-3.21) $p 0.006$ ] and the use of ceftriaxone [OR 2.2 (CI 1.28-3.78), $p$ 0.004] Table 3.

\section{Discussion}

The population referred has a high age, a high dependency rate, dementia, comorbidity, and malnutrition, and those conditions are similar to those described by other authors in similar populations [12-14]. Furthermore, we found a high prevalence of COVID-19 atypical symptoms such as delirium, functional impairment, or eating disorder with percentages around $20 \%$. Those percentages 
Table 1 Characteristics of the sample and according to the place of care

\begin{tabular}{|c|c|c|c|c|}
\hline Variable & $\begin{array}{l}\text { Total } \\
(\mathrm{N}=419)\end{array}$ & Nursing home $(\mathrm{N}=289)$ & $\begin{array}{l}\text { Hospital } \\
(\mathrm{N}=130)\end{array}$ & $p$-Value \\
\hline Median Age (Q1; Q3) & $89(84 ; 92)$ & $88(83 ; 92)$ & $89(84.5 ; 93)$ & 0.169 \\
\hline Gender. \% Female & 71.6 & 76.8 & 60 & $<0.001$ \\
\hline Male & 28.4 & 23.2 & 40 & \\
\hline Type of nursing home. \% Private & 68.2 & 68.5 & 67.7 & 0.868 \\
\hline \multicolumn{5}{|l|}{ Geriatric Assessment. \% } \\
\hline Barthel $<60$ & 63.7 & 73 & 43.9 & $<0.001$ \\
\hline FAC $<3$ & 54.6 & 63.1 & 34.3 & $<0.001$ \\
\hline GDS 6-7 & 43.8 & 54 & 22.4 & $<0.001$ \\
\hline Malnutrition & 64 & 62.9 & 66.3 & 0.574 \\
\hline Median Charlson (Q1; Q3) & $2(1,3)$ & $3(1 ; 4)$ & $2(1 ; 3)$ & 0.415 \\
\hline Median symptom evolution time (Q1; Q3) & $3(1 ; 7)$ & $3(1 ; 7))$ & $3(1 ; 6.8)$ & 0.141 \\
\hline \multicolumn{5}{|l|}{ Symptoms. \% } \\
\hline Cough & 30.1 & 28.4 & 33.8 & 0.258 \\
\hline Respiratory failure (SatO2 $\leq 92 \%)$ & 70.2 & 65.1 & 81.5 & $<0.001$ \\
\hline Tachypnea (FR $\geq 30$ rpm) & 18.9 & 16.6 & 23.8 & 0.08 \\
\hline Dyspnea & 16.2 & 12.8 & 23.8 & 0.005 \\
\hline Fever $\left(\operatorname{Ta}^{\mathrm{a}} \geq 38^{\circ} \mathrm{C}\right)$ & 44.2 & 42.6 & 47.7 & 0.328 \\
\hline Delirium & 19.6 & 20.4 & 17.7 & 0.516 \\
\hline Functional impairment & 20 & 15.6 & 30 & $<0.001$ \\
\hline Falls & 3.8 & 1.4 & 9.2 & $<0.001$ \\
\hline Eating Disorder & 18.6 & 18.3 & 19.2 & 0.828 \\
\hline \multicolumn{5}{|l|}{ Treatment \% } \\
\hline Hydroxychloroquine & 64.2 & 59.2 & 75.4 & 0.001 \\
\hline Lopinavir/Ritonavir & 5 & 0 & 16.2 & $<0.001$ \\
\hline Azithromycin & 53.2 & 48.1 & 64.6 & 0.002 \\
\hline Ceftriaxone & 29.4 & 21.1 & 47.7 & $<0.001$ \\
\hline Amoxicillin-Clavulanic Acid & 25.5 & 23.5 & 30 & 0.16 \\
\hline Other Antibiotics & 28.4 & 20.8 & 45.4 & $<0.001$ \\
\hline Corticosteroids & 26.7 & 18 & 46.2 & $<0.001$ \\
\hline HBPM & 24.1 & 6.6 & 63.1 & $<0.001$ \\
\hline 60 -day mortality $\%$ & 36.8 & 34.9 & 40.8 & 0.253 \\
\hline Visits to emergency department 60 days \% & 22 & 8.3 & 20.2 & $<0.001$ \\
\hline Hospital admissions 60 days \% & 7.2 & 4.5 & 13.2 & 0.002 \\
\hline \multicolumn{5}{|l|}{ Place of Death. \% (N 154) } \\
\hline Nursing home & 70.1 & 98 & 16.9 & $<0.001$ \\
\hline Hospitalization ward & 24.7 & 1 & 69.9 & \\
\hline Emergency department & 3.3 & 1 & 7.5 & \\
\hline Palliative care unit & 1.9 & 0 & 5.6 & \\
\hline
\end{tabular}

were similar to other studies in institutionalized patients with COVID-19 $[6,15]$.

Almost a third of the assessed patients were referred to the hospital. These referrals were associated with a better functional and cognitive situation, the presence of severe symptoms, and the prescription of a specific treatment. A higher hospital referral was also observed in male patients in contrast to the data from Bielza [7].
Therefore, we analyzed characteristics based on gender, observing that institutionalized men with COVID-19 were younger and suffered less functional or cognitive impairment, which could justify this finding.

Additionally, referred patients to the hospital presented serious signs and symptoms of SARS-CoV-2 infection such as respiratory failure, fever, or tachypnea, also described in other studies $[7,8,12]$. The inhospital mortality rate was $27.7 \%$, similar to other 
Table 2 Characteristics of the sample according to mortality at 60 days - Univariate analysis

\begin{tabular}{|c|c|c|c|}
\hline Variable & Alive $(N=265)$ & Dead $(N=154)$ & p value \\
\hline Median Age (Q1; Q3) & $88(84 ; 92)$ & $90(85 ; 93.3)$ & 0.043 \\
\hline Gender. \% Female & 72.5 & 70.1 & 0.611 \\
\hline Type of nursing home. $\%$ private & 68.3 & 68.2 & 0.980 \\
\hline \multicolumn{4}{|l|}{ Geriatric Assessment. \% } \\
\hline Barthel $<60$ & 57.3 & 75 & $<0.001$ \\
\hline$F A C<3$ & 46.8 & 69.4 & $<0.001$ \\
\hline GDS 6-7 & 39.9 & 50.7 & 0.026 \\
\hline Malnutrition & 59.8 & 72.2 & 0.026 \\
\hline Median Charlson (Q1; Q3) & $2(1 ; 3)$ & $2(1 ; 3.3)$ & 0.129 \\
\hline Median symptom evolution time (days) (Q1; Q3) & $3(1 ; 7)$ & $3(1 ; 6.8)$ & 0.486 \\
\hline \multicolumn{4}{|l|}{ Symptoms. $\%$} \\
\hline Cough & 32.1 & 26.6 & 0.241 \\
\hline 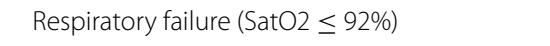 & 64.5 & 79.9 & $<0.001$ \\
\hline Tachypnea (FR $\geq 30$ rpm) & 12.1 & 30.5 & $<0.001$ \\
\hline Dyspnea & 12.1 & 23.4 & 0.002 \\
\hline Fever $\left(T^{\mathrm{a}} \geq 38^{\circ} \mathrm{C}\right)$ & 36.2 & 57.4 & $<0.001$ \\
\hline Delirium & 16.2 & 25.3 & 0.024 \\
\hline Functional impairment & 20.4 & 19.5 & 0.825 \\
\hline Falls & 4.5 & 2.6 & 0.32 \\
\hline Eating Disorder & 15.5 & 24 & 0.030 \\
\hline Referral to emergency department \% & 29.1 & 34.3 & 0.253 \\
\hline \multicolumn{4}{|l|}{ Treatment $\%$} \\
\hline Hydroxychloroquine & 64.9 & 63 & 0.693 \\
\hline Lopinavir/Ritonavir & 4.9 & 5.2 & 0.896 \\
\hline Azithromycin & 54.3 & 51.3 & 0.548 \\
\hline Ceftriaxone & 22.6 & 40.9 & $<0.001$ \\
\hline Amoxicillin-Clavulanic Acid & 25.7 & 25.3 & 0.939 \\
\hline Other Antibiotics & 27.2 & 30.5 & 0.464 \\
\hline Corticosteroids & 23.4 & 32.5 & 0.043 \\
\hline HBPM & 24.9 & 22.7 & 0.615 \\
\hline
\end{tabular}

Table 3 Multiple logistic regressions analysis* of 60-day mortality

\begin{tabular}{llll}
\hline Variable & OR & $\mathbf{9 5 \%} \mathbf{C l}$ & $\mathbf{p}$-Value \\
\hline Age (by years) & 1.05 & $1.01-1.09$ & 0.010 \\
Barthel Index $<60$ & 2.57 & $1.4-4.7$ & 0.002 \\
Tachypnea & 2.12 & $1.12-4.01$ & 0.021 \\
Fever & 1.9 & $1.21-3.21$ & 0.006 \\
Ceftriaxone & 2.2 & $1.28-3.78$ & 0.004 \\
\hline
\end{tabular}

*The variables included in the multivariate analysis were: age, sex, Barthel, GDS, respiratory failure, tachypnea, dyspnea, fever, delirium, eating disorder, use of ceftriaxone, corticosteroids, and hospital referral

studies of hospitalized older patients with percentages between $27 \%$ and $49 \%[16,17]$.

Few studies assess mortality at two months in institutionalized patients with COVID-19. In a study carried out in Italy, there was an excess of mortality observed in the months of March and April 2020 in a nursing home, with a mortality of $43 \%$ among patients with COVID-19 [18]. The mortality observed in our population at 60 days was $36.8 \%$, a percentage similar to that described in other studies that evaluated mortality at 30 days, finding a rate between 20 and $48 \%$ in institutionalized older persons patients $[8,15,19,20]$.

The mortality at 60 days in our study was related to age, functional dependence, the presence of tachypnea or fever, and the use of ceftriaxone. In other studies, age, dementia, frailty, fever, and respiratory symptoms have been associated with higher mortality $[7,8,12$, 21-24]. The relationship between mortality and the use of ceftriaxone, not described in previous studies, could be explained since it is a drug for intravenous or intramuscular administration, which was used in case 
of inability of oral feeding, therefore assuming a greater severity.

In our study, we did not find differences in mortality at 60 days according to the place of care, data similar to that referred by Bielza [7] or by España, [22] nor its association with male gender or the time of onset of COVID-19 symptoms. The fact of not finding differences in mortality depending on the place of care of the patients, enhances the importance of Liaison geriatric hospital-based team, as key in charge of the comprehensive and individualized assessment of each patient and the most appropriate management, thus avoiding unnecessary admissions and therapeutic fierceness.

The coordination between NH, primary care, and hospital care has been key during the pandemic. A study carried out in France in three nursing homes highlights that those nursing homes that received support from the hospital had lower mortality [25] Furthermore, after the first wave, this new form of work and collaboration has served to implement worldwide new strategies with to improve the care of the older persons living in, such as the formation of liaison geriatric hospital-based team units in our region [9].

The strengths of this study are the large sample size, as well as the multiple variables collected, which have made it possible to obtain results according to previous publications. Moreover, a follow-up of 60 days has been performed, higher than the studies published so far since we consider the impact of the disease on mortality could be better evaluated in a longer period.

The main limitation of our study is that it is retrospective, based on the information recorded in the electronic medical record. Furthermore, not all COVID-19 cases were confirmed by diagnostic test due to the limited access, and only the cases in which the nursing home health professionals requested the assessment of the liaison geriatrician were included. This could mean that we had not detected some older patients who could have been included in the study. Also, we could not collect symptomatic treatment or palliative sedation due to the lack of systematic inclusion in the patient's medical history. Institutionalized patients did not have advance care directives, so this information could not be used, which on the other hand, would have facilitated decision-making.

\section{Conclusions and implications}

The institutionalized patients evaluated by the liaison geriatric hospital-based team for suspected COVID-19, who were referred to the hospital, presented a better functional and cognitive situation and more frequently received specific treatment for the infection. However, no differences in mortality were found with patients treated in the nursing home. More than a third of the patients had died at 60 days, with higher mortality in those considered the oldest, the most dependent, and those who had presented symptoms such as fever and tachypnea. These findings suggest that the figure of the liaison Geriatrist has been important when individually determining the most appropriate management for each patient.

\section{Abbreviations}

COVID-19: Infection by SARS-CoV-2; NH: Nursing home; FAC: Functional Assessment Classification; GDS: Reisberg's Global Deterioration Scale for dementiastaging; BMl: Body mass index.

\section{Acknowledgements}

The authors thank the health care staff from the nursing homes and the medical staff of the Geriatrics Department of Hospital Universitario Ramón y Cajal. The authors also express their acknowledgment to Ana López Iglesias and Paula Sobrini Morillo for contributing in the acquisition of the data.

\section{Authors' contributions}

all authors meet the criteria for authorship stated in the Uniform Requirements for Manuscripts Submitted to Biomedical Journals, have read and approved the final manuscript and specific areas of contributions are declared LGC: conception and design of the study, acquisition, analysis and interpretation of the data and writing of the manuscript. NPA: acquisition of the data, conception and design of the study and writing of the manuscript. BME: writing the manuscript and revising manuscript critically for important content. LRC: conception and design of the study, acquisition of the data, writing the manuscript and revising manuscript critically for important content. JMN: conception and design of the study, analysis and interpretation of the data, writing the manuscript and revising manuscript critically for important content. ACJ: conception and design of the study and revising manuscript critically for important content. All authors have read and approved the manuscript.

Funding

this research did not receive any funding from agencies in the public, commercial, or not-for-profit sectors.

\section{Availability of data and materials}

The datasets used and/or analyzed during the current study are available from the corresponding author on reasonable request.

The manuscript has not been and will not be submitted, in part or entirely, elsewhere for publication and if accepted, the paper will not be published elsewhere.

\section{Declarations}

\section{Ethics approval and consent to participate}

The study was approved by the local Ethics Committee (approved June 8, 2020, act 393). Informed consent was waived for this retrospective study. All the ethical principles for medical investigation in human beings recorded in the Helsinki declaration of the World Medical Association were followed.

\section{Consent for publication}

not applicable.

Competing interests

There is no conflict of interest in any of the authors of the manuscript. 


\section{Author details}

${ }^{1}$ Unidad de Cuidados Paliativos, Hospital Universitario Ramón y Cajal (IRYCIS), Carretera de Colmenar km 9,1, 28034 Madrid, Spain. ${ }^{2}$ Servicio de Geriatría. Hospital Universitario Ramón y Cajal (IRYCIS), Madrid, Spain.

Received: 28 July 2021 Accepted: 12 October 2021

Published online: 29 October 2021

\section{References}

1. Bonanad C, García-Blas S, Tarazona-Santabalbina F, et al. The Effect of Age on Mortality in Patients With COVID-19: A Meta-Analysis With 611,583 Subjects. J Am Med Dir Assoc. 2020;21(7):915-8. https://doi.org/10.1016/j. jamda.2020.05.045.

2. Onder G, Rezza G, Brusaferro S. Case-Fatality Rate and Characteristics of Patients Dying in Relation to COVID-19 in Italy [published correction appears in JAMA. 2020 Apr 28;323(16):1619]. JAMA. 2020;323(18):17751776. doi:https://doi.org/10.1001/jama.2020.4683

3. Abrams HR, Loomer L, Gandhi A, Grabowski DC. Characteristics of U.S. Nursing Homes with COVID-19 Cases. J Am Geriatr Soc. 2020;68(8):16536. https://doi.org/10.1111/jgs.16661.

4. Ministerio de derechos sociales y agenda 2030. Informe del grupo de trabajo COVID 19 y Residencias. Available in: https://www.mscbs.gob.es/ ssi/imserso/docs/GTCOVID_19_RESIDENCIAS.pdf. Accessed 6 February, 2021

5. Aw D, Woodrow L, Ogliari G, Harwood R. Association of frailty with mortality in older inpatients with Covid-19: a cohort study. Age Ageing. 2020;49(6):915-922. doi:https://doi.org/10.1093/ageing/afaa184

6. Rutten JJS, van Loon AM, van Kooten J, et al. Clinical Suspicion of COVID19 in Nursing Home Residents: Symptoms and Mortality Risk Factors. J Am Med Dir Assoc. 2020;21(12):1791-1797.e1. doi:https://doi.org/10. 1016/j.jamda.2020.10.034

7. Bielza R, Sanz J, Zambrana F, et al. Clinical Characteristics, Frailty, and Mortality of Residents With COVID-19 in Nursing Homes of a Region of Madrid. J Am Med Dir Assoc. 2021;22(2):245-252.e2. doi:https://doi.org/ 10.1016/j.jamda.2020.12.003

8. Heras E, Garibaldi P, Boix M, et al. COVID-19 mortality risk factors in older people in a long-term care center [published online ahead of print, 2020 Nov 27]. Eur Geriatr Med. 2020;1-7. doi:https://doi.org/10.1007/ s41999-020-00432-w

9. Menéndez-Colino R, Argentina F, de Miguel AM, et al. Liaison geriatric hospital-based team with nursing homes in COVID time. A new coordination model arrived to stay Rev Esp Geriatr Gerontol. 2021:56(3):157-165. doi:https://doi.org/10.1016/j.regg.2021.01.002

10. Condes E, Arribas JR; COVID19 MADRID-S.P.P.M. group. Impact of COVID19 on Madrid hospital system. Enferm Infecc Microbiol Clin (Engl Ed). 2021;39(5):256-257. doi:https://doi.org/10.1016/j.eimc.2020.06.005

11. Bardi T, Gómez-Rojo M, Candela-Toha AM, et al. Rapid response to COVID19, escalation and de-escalation strategies to match surge capacity of Intensive Care beds to a large scale epidemic. Rev Esp Anestesiol Reanim (Engl Ed). 2021;68(1):21-27. doi:https://doi.org/10.1016/j.redar.2020.09. 003

12. Panagiotou OA, Kosar CM, White EM, et al. Risk Factors Associated With All-Cause 30-Day Mortality in Nursing Home Residents With COVID-19. JAMA Intern Med. 2021;181(4):439-448. doi:https://doi.org/10.1001/jamai nternmed.2020.7968
13. McMichael TM, Currie DW, Clark S, et al. Epidemiology of Covid-19 in a Long-Term Care Facility in King County, Washington. N Engl J Med. 2020;382(21):2005-2011. doi:https://doi.org/10.1056/NEJMoa2005412

14. Wang L, He W, Yu X, et al. Coronavirus disease 2019 in elderly patients: Characteristics and prognostic factors based on 4-week follow-up. $J$ Infect. 2020;80(6):639-645. doi:https://doi.org/10.1016/j.jinf.2020.03.019

15. Geriatric Medicine Research Collaborative. Age and frailty are independently associated with increased COVID-19 mortality and increased care needs in survivors: results of an international multi-centre study. Age Ageing. 2021;50(3):617-630. doi:https://doi.org/10.1093/ageing/afab026

16. Kennelly SP, Dyer AH, Noonan C, et al. Asymptomatic carriage rates and case fatality of SARS-CoV-2 infection in residents and staff in Irish nursing homes. Age Ageing. 2021;50(1):49-54. doi:https://doi.org/10.1093/ageing/afaa220

17. Brouns SH, Brüggemann R, Linkens AEMJH, et al. Mortality and the Use of Antithrombotic Therapies Among Nursing Home Residents with COVID19. J Am Geriatr Soc. 2020;68(8):1647-1652. doi:https://doi.org/10.1111/ jgs. 16664

18. Cangiano B, Fatti LM, Danesi L, et al. Mortality in an Italian nursing home during COVID-19 pandemic: correlation with gender, age, $A D L$, vitamin $D$ supplementation, and limitations of the diagnostic tests. Aging (Albany NY). 2020;12(24):24522-24534. doi:https://doi.org/10.18632/aging. 202307

19. Sun H, Ning R, Tao Y, et al. Risk Factors for Mortality in 244 Older Adults With COVID-19 in Wuhan, China: A Retrospective Study. J Am Geriatr Soc. 2020;68(6):E19-E23. doi:https://doi.org/10.1111/jgs.16533

20. Rutten JJS, van Loon AM, Joling KJ, et al. Covid-19 in verpleeghuizen [COVID-19 in nursing homes A study of diagnosis, symptomatology and disease course]. Ned Tijdschr Geneeskd. 2020;164:D5173. Published 2020 Jul 20.

21. Bousquet G, Falgarone G, Deutsch D, et al. ADL-dependency, D-Dimers, $\mathrm{LDH}$ and absence of anticoagulation are independently associated with one-month mortality in older inpatients with Covid-19. Aging (Albany NY). 2020;12(12):11306-11313. doi:https://doi.org/10.18632/aging. 103583

22. España PP, Bilbao A, García-Gutiérrez S, et al. Predictors of mortality of COVID-19 in the general population and nursing homes [published online ahead of print, 2021 Jan 5]. Intern Emerg Med. 2021;1-10. doi:https://doi.org/10.1007/s11739-020-02594-8

23. Dutey-Magni PF, Williams H, Jhass A, et al. COVID-19 infection and attributable mortality in UK care homes: Cohort study using active surveillance and electronic records (March-June 2020) [published online ahead of print, 2021 Mar 11]. Age Ageing. 2021;afab060. doi:https://doi.org/10. 1093/ageing/afab060

24. Ma Y, Hou L, Yang $X$, et al. The association between frailty and severe disease among COVID-19 patients aged over 60 years in China: a prospective cohort study. BMC Med. 2020;18(1):274. Published 2020 Sep 7. doi:https://doi.org/10.1186/s12916-020-01761-0

25. Tarteret $P$, Strazzulla A, Rouyer M, et al. Clinical features and medical care factors associated with mortality in French nursing homes during the COVID-19 outbreak [published online ahead of print, 2020 Dec 7]. Int J Infect Dis. 2020;104:125-131. doi:https://doi.org/10.1016/j.ijid.2020.12.004

\section{Publisher's Note}

Springer Nature remains neutral with regard to jurisdictional claims in published maps and institutional affiliations. 